\title{
Optimization model for perishable products with time-base demand,stand on Pareto boundary and uncertainty
}

\author{
Mehdi Safaei ${ }^{1^{*}}$ \\ ${ }^{1}$ Department of Industrial Engineering, Istanbul Gelisim University, 34215,Avcilar, Istanbul, Turkey.
}

\begin{abstract}
Optimizing the perishable food, supply chain, taking into account all aspects, such as location, time, inventory control and routing, has become one of the top research priorities in today's competitive market. The primary objective is to reduce the overallcost, and the second one is to diminish the probability of warehouses failing to maintain the product (storage waste), which in turn, maximizes product quality.In this research, the issue of integrated supply chainplanning has been investigated in which it is assumed that there is a central warehouse for food distribution. The model developed in the present study considers two contradictory objectives for supply chainoptimization.In this research, foods are classified into three categories with the rate of deterioration common, high and very high. The concept of Pareto boundary and a set of optimal responses have been used. Demand is defined as uncertain and dependent on two factors, the demand for the prior period and the remaining time until the expiration of the products. The research problem is solved with both NSGA-II and NRGA algorithms whose parameters of these two algorithms are optimized by the Taguchi method. The two efficient boundaries are created by the four criteria MID, DM, SM and NOS. Finally, concluded that the efficiency of the NSGA-II method in solving the research problem and forming an effective boundary is higher than the NRGA method.
\end{abstract}

Keywords

Supply Chain; Perishable Products; Uncertain Demand; NSGA II; NSGA; Pareto Boundary Solution.

\section{Introduction}

Most end-consumerproducts are delivered through a multilevel supply chain (SC).In which datainformation, raw materials, and parts are transferred from suppliers to manufacturers to create the final products.Then in different markets as well as by different distribution systems, it finally reaches the end consumers.Supply chain management (SCM) is a critical role in reducing costs and maximizing profit, the importance of which has been repeatedly emphasized in many studies. In general, the decisions that a chain management makes are divided into three categories[1]:

- Strategic decisions: With long-term impacts that generally include decisions on location and allocation.

- Tactical decisions:With medium-term impacts that generally include inventory and transportation decisions.

- Operational decisions: With routine effects, on workstation and route planning.

Before the emergence of the SC concept, each of the above decisions was taken individually; for each of these issues, modeling was performed and optimal responses to the decision variables were made [2]. However, with the development of the SC concept, a combination of the above-mentioned decision-making problems was put on the agenda [3].For example, the inventory-locating problem is one of the well-known issues in the SC debate where strategic and tactical decisions are made concurrently. Furthermore, the problem of inventory-routing and locating-routing are long-familiar issues that have received much attention in the research area[4].

In general, it can be said that solving SC problems individually leads to suboptimal answers, which is not necessarily the best answer for optimizing the entire SC. if the strategic, tactical, and operational decisions are modeled and taken separately; the optimal responses provided will not be the optimum response. As such, developing a model that covers all three of these decisions and provides an overall optimal response to all three levels of decision-making is needed, and this issue has received less attention in previous research[5].

The planning and optimization of the SC of perishable food, have also been morecomplex.The first reason is that the demand for these products is completely dependent on the quality, and the quality is relying on the expiration date of the products.Therefore, it is important to develop suitable models for optimizing location, inventory control and routing in these chains [6].On the other hand, in the perishable food SC, there are usually thousands of miles from farm to end consumer. These chains must be managed so that the best quality products reach their destination, given the time constraints and real-world uncertainties. A large number of processes in the SC for such products, and the need to comply with high standards, such as 
manufacturing, warehousing, and shipping, all indicate that failure to comply with any of the standards in this chain may It can bring irreparable damage to the SC body $[7,8]$.

In the present study, the issue of integratedSC planning has been investigated in which it is assumed that there is a central warehouse for food distribution. Foods are classified into three categories with the rate of deterioration common, high and very high.Products with the common rate of deteriorationare kept in a normal warehouse. High-deterioration rate products are stored in the refrigerator, and a veryhigh rate of deterioration will be kept in the freezer. Potential locations for wholesale warehouses are also identified, from which appropriate locations should be selected; the level of inventory available to each warehouse as well as the allocation of warehouses to customers. The research problem is defined as a two-objective model. The primary goal is to decrease the whole cost, and the other objective is to limit the chance of warehouses failing to store the product (storage waste), which in flip, maximizes product quality.Given that the research problem is NLP type and that the above two objectives are completely reversed and need optimal solutions in the form of efficient boundaries, both NSGA-II and NRGA algorithms are used to optimize the research problem. And the performance of these two algorithms is compared.

In the following, the research literature will be reviewed.Then a proposed model for this problem and its solution methodology is presented.Finally, the results are discussed and analyzed.

\section{Literature review}

Much research has focused on food chain optimization. Broekmeulen (1998) has proposed a MILP-based modeling approach to optimize the SC performance of vegetables and fruits and has investigated the efficiency of the proposed method using chain simulation[9].

Zhang et al. (2003) discuss the optimization of frozen-food quality in the SC. In the model presented by the researchers, maintenance and transportation costs are minimized throughout the chain and the quality of the frozen commodity that has the opposite relation to the corruption rate is maximized [[10].

Lucas, M., \& Chhajed (2004) investigated the optimization of locating agricultural farms using linear programming and presented a model for optimal locating of 6 farms in the real world[11]. Ahujaet al. (2007) Optimized the problem of retailer allocation to wholesalers and rooted the distribution of goods by considering the time constraint for distributing perishable goods using nonlinear scheduling[12].
Ahumada and Villalobos (2009) and Akkerman\&Grunow(2011) have developed a linear programming model to optimize the location and routing problem for perishable products [13, 14].

Zanoni et al. (2012) propose a model for SC optimization in which the quality of perishable goods is changed by temperature and shelf life and optimize quality and total cost as two objectives[15].

Nagurney and Masoumi (2012) modeled and optimized the SC as a perishable commodity using linear programming, designing a sustainable type of chain (green chain goals, social responsibility, and cost)[16].

Agustina et al. (2014) have used the complex linear programming problem to optimize routing and inventory control in the perishable food SC. Researchers have designed the issue for two purposes with cost and quality goals, and have considered quality to be influenced by the expiration date of products. Multivariate genetic algorithm is also used to solve the problem[17].

Lanfranchiet al. (2016) have also designed a threeobjective problem, including goals: minimizing delivery time, minimizing cost, and minimizing harmful gas emissions, for perishable products[18].

Mousavi and Amiri (2017) designed a sustainable green SC using complex integer programming and used the NSGA-II algorithm to solve it. Researchers have defined the quality of food as influenced by their novelty and time remaining until the products expire[19].

Rafi Majd et al. (2018) discuss three levels of strategic, tactical, and operational concurrent decision making about perishable products[20].Tavana et al. (2018) have examined the problem of SC of perishable goods with social and humanitarian benefits in precrisis and post-crisis situations. This research problem is solved in a multi-objective manner using the NSGAII algorithm[21].

Hsu (2019) has used the quality of perishable products as anSC objective and developed a twoobjective SC model using linear programming[22].Liet al. (2019) have developed a three-level SC problem with locating, routing and inventory objectives and have proposed a multi-step heuristic based on Simulated Annealing algorithm for perishable goods[23].

Guo et al. (2019) have presented a nonlinear programming model to solve the problem of locating, routing, and inventory in a closed SC and compared the performance of the nonlinear programming method in comparison to the combined genetic algorithm and simulated annealing algorithm[24]. 
According to the research literature, there is a need for a model that is capable of simultaneously addressing the conflicting multi-objective SC problem (by reducing costs and reducing the number of corrupt goods and increasing quality), as well as, taking into account uncertain demandin perishable products and grading of the degree of commodity corruption, to optimize the chain inventory, dependent on the time remaining from the expiry date of products in the warehouse.In addition, in this paper, to improve the accuracy of the responses, the Pareto boundary concept is used to provide a set of optimal responses.In the meantime, this paper has attempted to solve this model by two algorithms and evaluated their response accuracy, and by the Taguchi method, the structure of these algorithms has been improved.

\section{Research Methodology}

At the beginning of this section, the proposed research model is presented and then a description of the proposed model solving methods using both NSGA and NRGA algorithms.

\subsection{Proposed model}

In the following, the parameters are given in table (1).

Table 1: Parameters

\begin{tabular}{|c|c|}
\hline Parameters & Description \\
\hline$F_{f}$ & $\begin{array}{l}\text { Fixed cost of } \\
\text { creating } \\
\text { warehousej }\end{array}$ \\
\hline$F O C_{k t}$ & $\begin{array}{l}\text { Central } \\
\text { warehouse } \\
\text { fixed cost of } \\
\text { ordering } \\
\text { product } k \text { in } \\
\text { period } t\end{array}$ \\
\hline$W P_{k t}$ & $\begin{array}{l}\text { Wholesale } \\
\text { purchase } \\
\text { cost of the } \\
\text { goods }(\mathrm{k}) \text { by } \\
\text { the central } \\
\text { warehouse }\end{array}$ \\
\hline$F T C_{j t}$ & $\begin{array}{l}\text { Fixed } \\
\text { transport } \\
\text { cost to } \\
\text { warehouse } \mathrm{j} \\
\text { by the } \\
\text { central } \\
\text { warehouse } \\
\text { in timet }\end{array}$ \\
\hline
\end{tabular}

\begin{tabular}{|c|c|}
\hline$T C W_{j k t}$ & $\begin{array}{l}\text { Cost of } \\
\text { transportfor } \\
\text { goodsk, } \\
\text { from the } \\
\text { central } \\
\text { warehouse } \\
\text { to } \\
\text { warehouse j } \\
\text { in time t }\end{array}$ \\
\hline$T C R_{k i j t}$ & $\begin{array}{l}\text { Cost of } \\
\text { shipping for } \\
\text { goodsk, } \\
\text { from } \\
\text { warehouse } \mathrm{j} \\
\text { to clienti, in } \\
\text { time t }\end{array}$ \\
\hline$H C W_{k j t}$ & $\begin{array}{l}\text { Cost of } \\
\text { maintaining } \\
\text { for goodsk, } \\
\text { in } \\
\text { warehouse j, } \\
\text { in time t }\end{array}$ \\
\hline$H C R_{k t}$ & $\begin{array}{l}\text { Cost of } \\
\text { warehousing } \\
\text { of goodsk, in } \\
\text { central } \\
\text { warehouse } \\
\text { in time t }\end{array}$ \\
\hline$S C_{\text {kit }}$ & $\begin{array}{l}\text { The cost of } \\
\text { the shortage } \\
\text { of goodsk, } \\
\text { for clienti, in } \\
\text { time t }\end{array}$ \\
\hline$E C R_{k j t}$ & $\begin{array}{l}\text { Expiration } \\
\text { cost of } \\
\text { goodsk in } \\
\text { warehouse } \mathrm{j} \\
\text { in time } \mathrm{t}\end{array}$ \\
\hline$E C W_{k t}$ & $\begin{array}{l}\text { Cost of } \\
\text { expiration of } \\
\text { goodsk in } \\
\text { central } \\
\text { warehouse } \\
\text { in time t }\end{array}$ \\
\hline$L C_{k i j t}$ & $\begin{array}{l}\text { Cost of } \\
\text { reducing } \\
\text { unit demand } \\
\mathrm{k} \text { due to } \\
\text { unfavorable } \\
\text { conditions of } \\
\text { expiry date } \\
\text { in } \\
\text { warehouse } \mathrm{j} \\
\text { for clienti in } \\
\text { time t }\end{array}$ \\
\hline$V_{k}$ & Volume of \\
\hline
\end{tabular}




\begin{tabular}{|l|l|}
\hline $\boldsymbol{N T}_{k}$ & goodsk \\
\hline Fixed time \\
required for \\
ordering \\
goodsk \\
(research \\
and \\
negotiations \\
and so on) \\
Availability \\
of goodsk of \\
type s (s \\
represents \\
the class of \\
goods \\
storage \\
conditions) \\
Available \\
capacity of \\
goodsk of \\
type s in \\
central \\
warehouse
\end{tabular}

Also, the variables used in the research model are presented in Table (2).

Table 2: Variables used in the model

\begin{tabular}{|c|c|}
\hline Variables & Description \\
\hline$Y_{f}$ & $\begin{array}{l}\text { Binary } \\
\text { variable } \\
\text { creating } \quad \text { a } \\
\text { warehouse j }\end{array}$ \\
\hline$Z_{k t}$ & $\begin{array}{l}\text { Banner } \\
\text { variable } \\
\text { ordering } \\
\text { goodsk in } \\
\text { time t by } \\
\text { central } \\
\text { warehouse }\end{array}$ \\
\hline$q_{k t}$ & $\begin{array}{l}\text { Order volume } \\
\text { of goodsk, by } \\
\text { central } \\
\text { warehouse in } \\
\text { time t }\end{array}$ \\
\hline$X_{f t}$ & $\begin{array}{l}\text { Binary } \\
\text { variable } \\
\text { sending order } \\
\text { to warehouse } \mathrm{j} \\
\text { in time } \mathrm{t}\end{array}$ \\
\hline$u_{j s k t}$ & $\begin{array}{l}\text { Number of } \\
\text { goodsk that } \\
\text { shipped to } \\
\text { warehouse } \mathrm{j} \text { in } \\
\text { time } t \text { related } \\
\text { to terms of }\end{array}$ \\
\hline
\end{tabular}

\begin{tabular}{|c|c|}
\hline & storage s. \\
\hline$v_{k i j t}$ & $\begin{array}{l}\text { Number of } \\
\text { goodsk that } \\
\text { sent from } \\
\text { warehouse } \mathrm{j} \text { to } \\
\text { clienti in time } \\
\mathrm{t}\end{array}$ \\
\hline$I_{k j t}$ & $\begin{array}{l}\text { Inventory of } \\
\text { the goodsk in } \\
\text { warehouse } \mathrm{j} \text { at } \\
\text { the end of } \\
\text { time } \mathrm{t}\end{array}$ \\
\hline$I_{k t}$ & $\begin{array}{l}\text { Inventory of } \\
\text { the goodsk in } \\
\text { the central } \\
\text { warehouse at } \\
\text { the end of } \\
\text { time t }\end{array}$ \\
\hline$b_{\text {kit }}$ & $\begin{array}{l}\text { The amount } \\
\text { of shortage of } \\
\text { goodsk for } \\
\text { client I in time } \\
t\end{array}$ \\
\hline$E P_{k j t}$ & $\begin{array}{l}\begin{array}{l}\text { Number } \\
\text { expired } \\
\text { goodsk } \\
\text { warehouse } \\
\text { for time t }\end{array} \\
\end{array}$ \\
\hline$D_{\text {kit }}$ & $\begin{array}{l}\text { Demand of } \\
\text { goodsk by } \\
\text { clienti in time } \\
t\end{array}$ \\
\hline$W_{\text {kijt }}$ & $\begin{array}{l}\text { Fixed } \\
\text { shipping cost } \\
\text { from } \\
\text { warehouse j to } \\
\text { clienti for } \\
\text { goodsk in } \\
\text { time t }\end{array}$ \\
\hline$E P_{k j t}$ & $\begin{array}{l}\text { Number of } \\
\text { expired } \\
\text { goodsk in } \\
\text { warehouse } \mathrm{j} \text { in } \\
\text { time } \mathrm{t}\end{array}$ \\
\hline$N E P_{s k j t}$ & $\begin{array}{l}\text { Number of } \\
\text { goodsk, close } \\
\text { to expiration } \\
\text { conditions in } \\
\text { warehouse } \mathrm{j} \text { at } \\
\text { time t }\end{array}$ \\
\hline
\end{tabular}

Using the parameters and variables mentioned, the research model is developed as follows. 


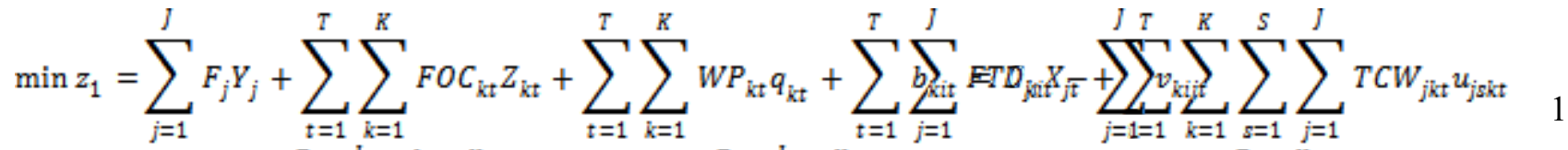

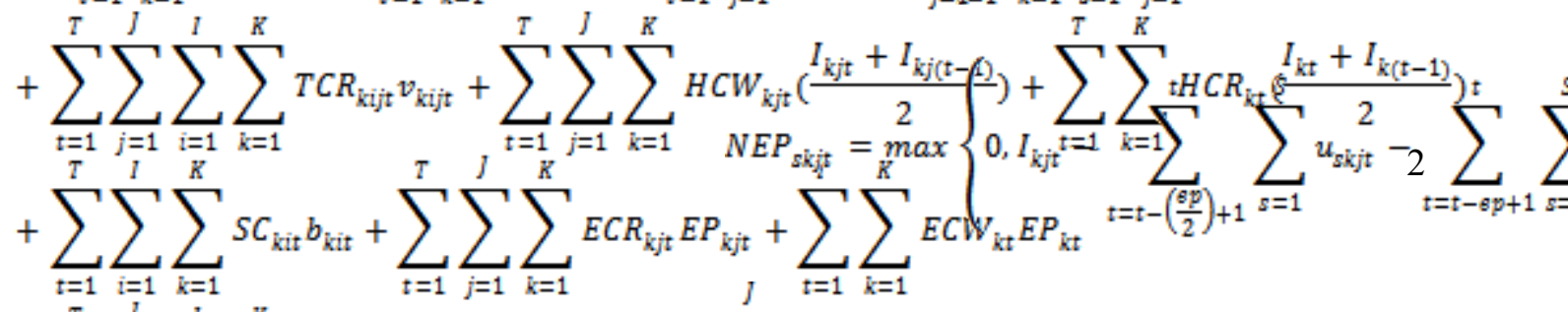

$$
\begin{aligned}
& +\sum_{\mathrm{t}=1}^{T} \sum_{j=1}^{J} \sum_{i=1}^{I} \sum_{k=1}^{K} w_{k i j t}\left(D_{k i t}-D_{k i(t-1)}\right) L C_{k i j t} \sum_{j=1}^{J} v_{k i j t} \leq D_{k i t} \\
& \begin{array}{r}
\min Z_{2}=\sum_{j} y_{j} \delta_{j}-\sum_{j 1 \neq j 2} \sum_{j 2} y_{j 1} y_{j 2} \delta_{j 1} \delta_{j} \\
+\sum_{j 1 \neq j 2 \neq-\neq j m} \cdots \sum_{j m-2 \neq j m-} \\
\sum_{k} V_{k} u_{j o k}+\sum_{k} V_{k} I_{s k j(t-1)} \leq C R_{s k} Y_{j}
\end{array}
\end{aligned}
$$$$
\sum_{k} V_{k} q_{s k h}+\sum_{k} V_{k} I_{s k(t-1)} \leq C W_{s k} Y_{j}
$$$$
\sum_{j=1}^{I} \sum_{s=1}^{S} u_{s k j t} \leq T R_{k} Z_{k t}
$$

$\sum_{i=1}^{I} v_{k i j t} \leq I_{k j j(t-1)}+\sum_{g=1}^{S} u_{s k j t}$

$I_{k j \mathrm{j}}=I_{k j \mathrm{j}(\mathrm{t}-1)}+\sum_{s=1}^{S} u_{s k j t}-\sum_{i=1}^{I} v_{k i j \mathrm{j}}-E P_{k j \mathrm{j} t}$

$I_{k t}=I_{k(t-1)}-\sum_{j=1}^{I} \sum_{s=1}^{S} u_{s k j t}+q_{k t}-E P_{k t}$

$E P_{k j t}=\max \left\{0, I_{k j t}-\sum_{t=t-s p+1}^{t} \sum_{s=1}^{s} u_{s k j t}\right\}$

$E P_{k t}=\max \left\{0, I_{k t}-\sum_{t=t-s p+1}^{t} \sum_{s=1}^{S} u_{s k t}\right\}$$$
I_{s \mathrm{kj} 0}=0
$$$$
I_{s \mathrm{k} 0}=0
$$

$$
D_{k i t}=G R D_{k i(t-1)}-\frac{e^{\left(\frac{N E P_{s k j(t-1)}}{\left.I_{k j f(t-1)}\right)}\right.}}{e^{\left(\frac{b_{k i(t-1)}}{D_{k i t}(-1)}\right)}+\varepsilon_{t}}
$$

\subsection{Solving methodology}

To solve the research model, two meta-heuristic NSGA II and NRGA will be used.Both methods are developed from genetic algorithms and are used to solve multi-objective models and produce efficient boundaries.In this section, the general structure of these two algorithms will be introduced.The main reason for using the evolutionary NSGA-II algorithm for multi-objective optimization problems is its ability to deal with the set of feasible solutions and find the optimal Pareto level at each run of the algorithm. The NSGA-IIalgorithm was developed by Deb et al. In 2002 and is a modified version of the original NSGA algorithm, which is capable of faster computation and better convergence to achieve a non-recursive level compared to other evolutionary multi-objective algorithms.In table 3 , a comparison of the two algorithms is shown.

Table 3. Comparison of two algorithms(NSGA-II and NRGA 


\begin{tabular}{|c|c|c|}
\hline Characteristics & Algorithm \\
\hline Selection Approach & NSGA-II & NRGA \\
\hline Selection Methodology & One-phase & Two-phase selection \\
& selection method & Binary tournament \\
& Roulette wheel & method \\
\hline Selecting probability & method & Based on rank of \\
\hline & Based on rank of & solution \\
\hline
\end{tabular}

The steps to find non-recursive solutions by the NSGA II algorithm are as follows:

\section{Collecting parameters}

Model parameters include: number of objective functions, number of constraints and also the number of independent variables.

Specific parameters include:parameters used in the research model regarding ordering, maintenance, demand rate, etc.

\section{Selecting the parameters of the Genetic Algorithm (GA)}

Adjust the population size N, adjust the number of generations, adjust the probability of crossovers and mutations, and adjust the minimum and maximum variables.

\section{Creating the initialpopulation}

Solution coding: The information reflected on the chromosome should consist of two parts: 1) the number of products shipped from each type to each warehouse and from each warehouse to each customer in each time period 2) the decision on warehousing and ordering anytype products.

\section{Genetic operators}

Crossover operator:crossover is one of the main operators in genetic patterning and needs to be set up correctly. The way it works is that based on the rate of intersection defined in the parameters, chromosomes are selected from the initial population. Then a random number is created between zero and one, and this number occurs between the two selected weighted algebraic chromosomes and the new chromosome.
Mutation operator: The mutation operator is applied to the list of methods specific to each activity. For the list of methods, each execution method activity is randomly selected by re-selecting one method from among the available methods. In more detail, based on the mutation rate of a number of chromosomes selected from the primary population, it is modified based on a random number of one of the genes and then the mutated chromosome is created by observing the minimum and maximum variables.

Using the above operators, the child population is formed.

\section{Population composition}

The parent and child populations that were formed in the previous step are combined and form the Archive.

\section{Formation of Pareto surface boundary layers}

For all members of the Archive collection, all theobjective functions listed are calculated.

After calculating all the objective functions for the members of the Archive set, each member is given a level number by sorting the members by the undesirable level.

\section{Sort each level by density (congestion distance)}

Since individuals are selected based on their surface number and density (congestion distance), all individuals in the population are assigned the density value (density interval). Calculate the density by the following formula. 


$$
c d_{i}=\sum_{k=1}^{r} \frac{f_{k, i+1}-f_{k, i-1}}{f_{k}^{\max }-f_{k}^{\min }}
$$

In this formula, $\mathrm{K}$ is the number of target functions and $\mathrm{i}$ for each member in the Archive set. $f^{m}$ and

$f^{n}$ are the maximum and minimum calculated values of the objective function $\mathrm{k}$. A large amount of this parameter will result in better divergence and range in the population set.

\section{Create the next generation}

The next generation of $\mathrm{N}$ is made up of the combined population by comparing the number of Pareto surface layers and the density value.Accordingly, if the two members selected were from two different levels, a member with a lower-level number (the solutions at the lower-level number are better and non-dominant solutions) will be selected.Now if both members have the same level number, then the one with the greatest congestion distance is selected. This will increase the dispersion of the answers.

The above steps will continue until the condition is
Another algorithm used in this research is the NRGA algorithm. The difference between this algorithm and the NSGA-II algorithm is in the use of the Roulette cycle. This algorithm uses the Roulette cycle to apply the intersection operator. With the Roulette cycle, the better answers are more likely to be chosen, not necessarily selected.

\section{Parameter setting}

The proper design of parameters and operators has a great impact on the performance of the algorithms used. One of the methods used is Taguchi designs. Two of the main goals of the Taguchi designs are to minimize the effect of perturbation factors and to determine the level of controllable factors.In this method, after the design of the experiment, the results of each experiment are analyzed.Taguchi suggests analyzing mean responses. The amount of changes can also be analyzed using Signal to Noise ratios (SN).Between ratios, three ratios are considered as standard ratios.Now, since most of the objective functions of the scheduling problem are the least desirable, so the ratio is calculated using the following formula:

$S N_{S}=-10 \log \left(\frac{1}{N} \sum_{i=1}^{n}\right.$ objectivefunction $\left.{ }_{i}^{2}\right)$

\begin{tabular}{|c|c|c|c|c|}
\hline Factors & Signs & Level 1 & Level 2 & Level 3 \\
\hline NPop & A & 25 & 50 & 100 \\
\hline Pc & B & 0.7 & 0.75 & 0.8 \\
\hline Pm & C & 0.2 & 0.3 & 0.5 \\
\hline MaxIt & D & 25 & 50 & 100 \\
\hline
\end{tabular}

terminated.

The termination situation is defined as follows:

- Failure to enter a new solution to the effective boundary formed after several specific steps.

- Set the maximum number of algorithm iterations and finish the algorithm after the number of iterations.
Population number (npop), crossover probability $(\mathrm{Pc})$, probability of mutation (Pm) and maximum iteration; four controllable factors for the proposed algorithm. There are three levels for each of these factors. Table (4) shows the agents and their levels.

Table 4: The factors and the level of each 
Therefore, according to the Taguchi method, 9 designs are selected for four factors with three levels

(Table 5).

Table 5: Designed experiments

\begin{tabular}{|c|c|c|c|c|}
\hline Experiment number & $\mathbf{A}$ & B & C & D \\
\hline 1 & 25 & 0.7 & 0.2 & 100 \\
\hline 2 & 25 & 0.75 & 0.3 & 50 \\
\hline 3 & 25 & 0.8 & 0.5 & 25 \\
\hline 4 & 50 & 0.7 & 0.5 & 50 \\
\hline 5 & 50 & 0.75 & 0.3 & 100 \\
\hline 6 & 50 & 0.8 & 0.2 & 25 \\
\hline 7 & 100 & 0.7 & 0.3 & 25 \\
\hline 8 & 100 & 0.75 & 0.2 & 50 \\
\hline 9 & 100 & 0.8 & 0.5 & 100 \\
\hline
\end{tabular}


Now by performing the above-designed experiments and repeating each of them for 3 times the mean values and disturbance alerts are calculated.The values obtained are shown in the following diagrams.Finally, by examining the Signal to Noise diagrams (SNs) and the mean ( ) level of each factor will be determined.Given the minimization of the objective function, it would be better if the Signal to Noise ratios and mean values were lower. Finally, a lower level will be selected.

\section{Methodological performance evaluation}

There are two categories of criteria for evaluating the performance of multi-objective meta-heuristic algorithms:

I. Qualitative criteria: Among the qualitative criteria can be mentioned the following:

Named Quality Metric (QM), Mean ideal distance(MID), Data envelopment analysis (DEA) and Number of non-dominated solutions (NOS).

II. Quantitative Criteria: Criteria for this category include the Diversification metric (DM), Spacing metric (SM).

In this study, four criteria of MID, DM, SM, and NOSPareto were used to evaluate two algorithms and compare their performance.

Mean ideal distance (MID): This measure calculates the proximity and distance of Pareto solutions to the ideal point. Therefore, better Pareto responses are obtained when the value of this criterion is lower.And the lower and lower the criterion, the Pareto answers are closer to the ideal answers. This criterion is calculated by the following relation:

$M I D=\frac{\sum_{i=1}^{n} \sqrt{\left(f_{1 i}-f_{1 b s s t}\right)^{2}-\left(f_{2 i}-f_{2 b s s t}\right)^{2}}}{n}$

Here, $\mathrm{n}$ is the number of non-dominated answers, $f_{1 b}$ and $f_{2 b}$ are ideal points.

Diversification metric (DM): Calculates this algorithm for Diversification non-dominated solutions. The higher this criterion indicates the more divergence in nondominated solutions. This criterion is calculated by the following relation:

$D M=\sqrt{\left(\min f_{1 \mathrm{i}}-\max f_{1 \mathrm{i}}\right)^{2}-\left(\min f_{2 \mathrm{i}}-\max f_{2 \mathrm{i}}\right)^{2}} 21$

Spacing metric (SM): This criterion calculates the relative distance of successive solutions. When the answers are evenly aligned, then the SM value will also decrease. Therefore, an algorithm with non-dominated solutions with a small amount of spacing is more desirable.

$S M=\frac{\sum_{i=1}^{n-1}\left|\bar{d}-d_{i}\right|}{(n-1) \bar{d}}$

In this formula is the Euclidean distance between points and is the mean of these distances.

A number of non-dominated solutions-Pareto(NOSPareto): This criterion determines the number of optimal solutions that each algorithm succeeds in finding. A higher value of this criterion indicates better algorithm performance.

In order to evaluate and prove the model performance, as well as to compare the two methods mentioned, two SC scenarios were simulated, in which 1 central distribution warehouse, and 10 wholesale warehouses, were randomly selected from 100 potential warehouses. And each of them will be randomly assigned, 100 customers. By running two algorithms separately, for each of the simulated SCs in both scenarios, an attempt is made to investigate the performance of both NSGA-II and NRGA algorithms.

\section{Research results}

To investigate the efficiency of the proposed research model, in this section, two SCs are simulated and the performance of both NSGA-II and NRGA algorithms is investigated.The simulated SC consists of 1 central warehouse for distribution of products, 10 wholesale warehouses comprised of 100 potential locations and 100 customers.

In the initial section, it is necessary to optimize the performance of the two proposed algorithms using the Taguchi method. This is shown in Fig. 1 and Fig. 2. 

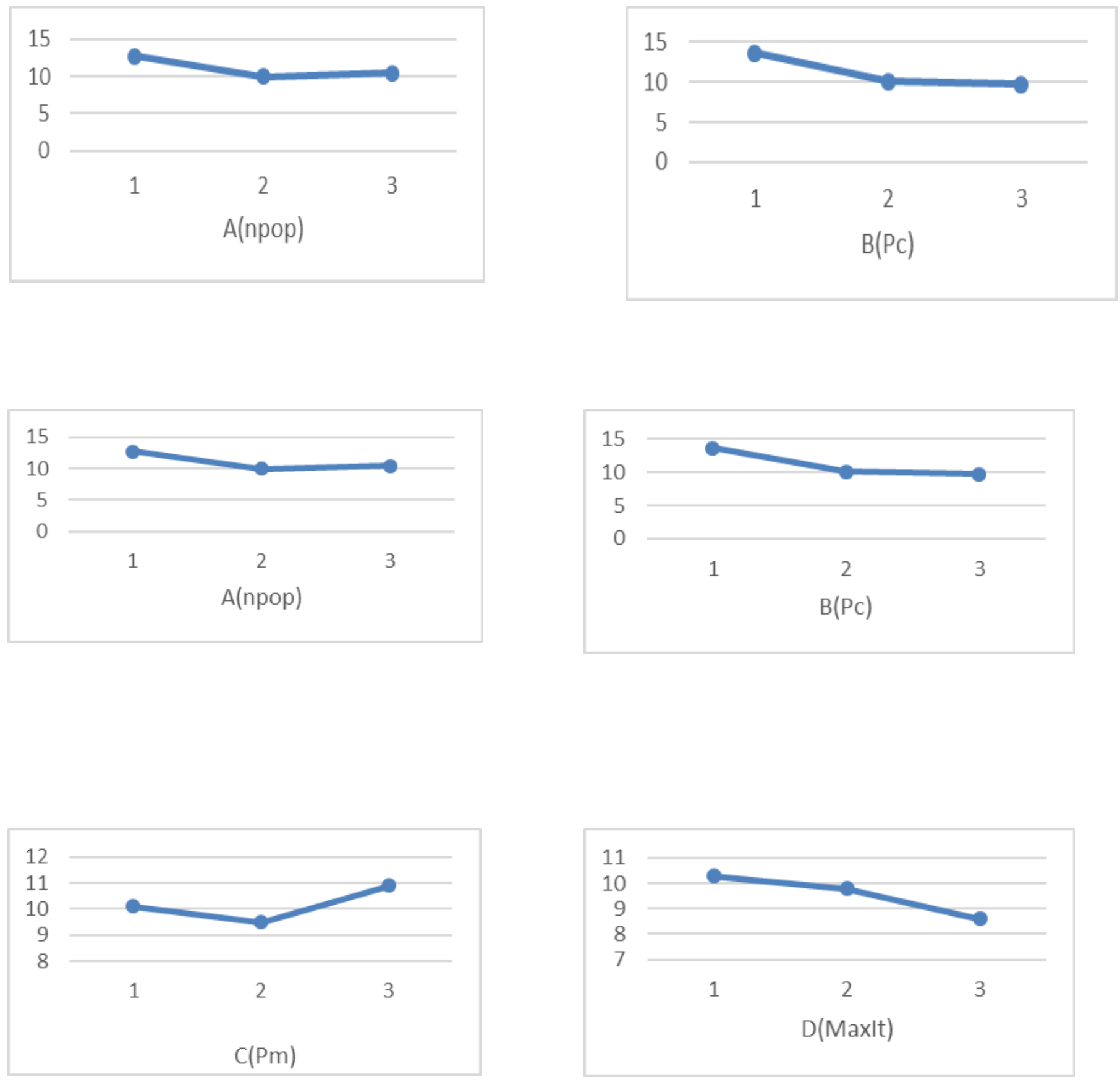

Figure 1: Signal to Noise ratios Taguchi method (optimal values are the minimum values) 

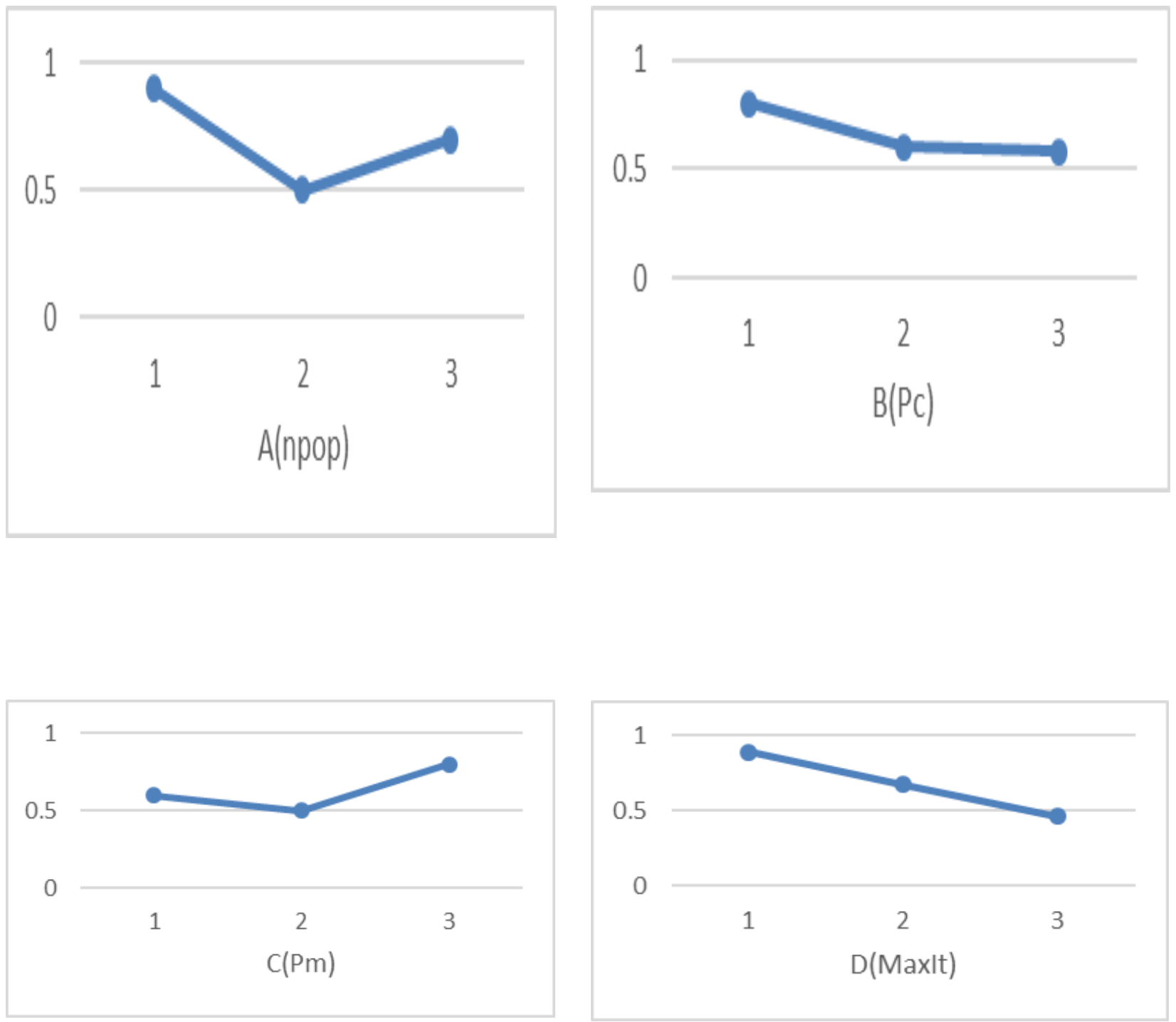

Figure 2: Graph of mean of Taguchi method (optimal values are the least values)

According to Figures 1 and 2, the optimal parameters of the two proposed research algorithms are as follows:

- Initial population: 50

- Crossover rate: 0.7

- Mutation rate: 0.3

- Number of Repeats: 100
Thus, using the identified optimal parameters, the research model is simulated, structured and solved by two NSGA-II and NRGA algorithms.The effective boundaries calculated by two research methods for two simulated chains are shown in the following figures: 

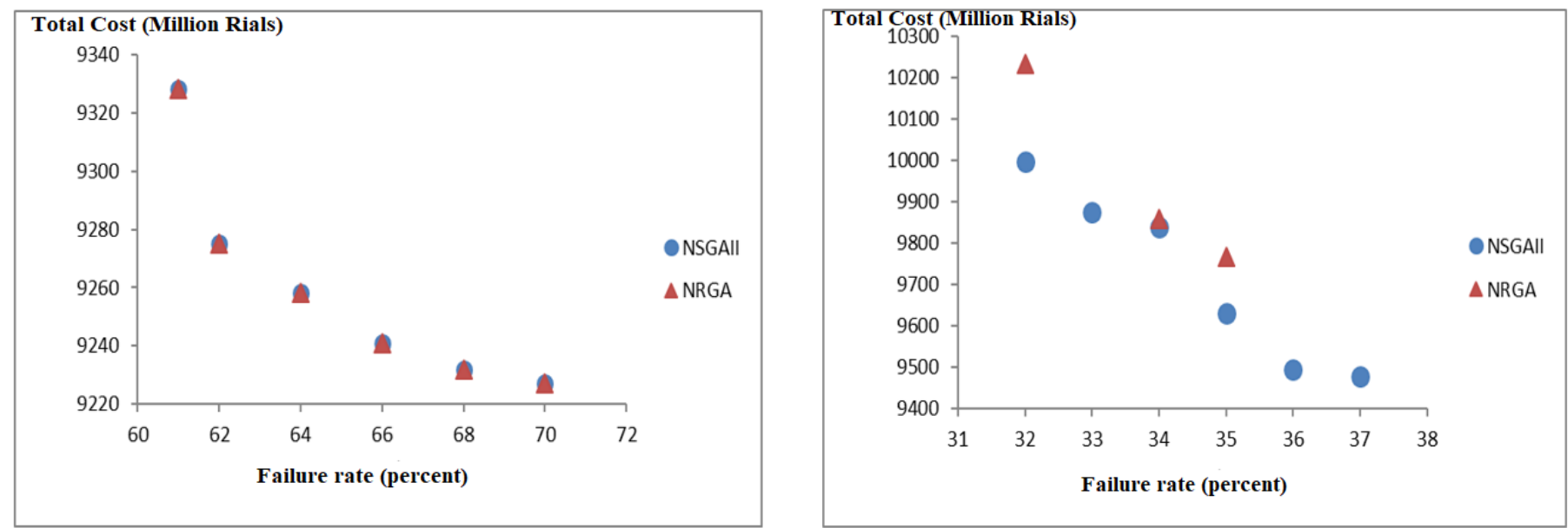

Figure 3: Comparison of efficient boundaries obtained from two proposed algorithms

But as is evident in the above figures, neither of the two methods has been completely superior to the other. Therefore, one of them cannot be selected as the best performing algorithm. For this purpose, the performance of the two algorithms will be compared using the four criteria developed in the previous section and according to the table 6 .

Table 3: Comparison of the performance of two research problem solving algorithms

\begin{tabular}{|c|c|c|c|c|c|c|c|c|}
\hline Scenario & \multicolumn{2}{|c|}{ MID } & \multicolumn{2}{|l|}{ DM } & \multicolumn{2}{|c|}{ SM } & \multicolumn{2}{|c|}{ NOS } \\
\hline number & NSGA-II & NRGA & NSGA-II & NRGA & NSGA-II & NRGA & NSGA-II & NRGA \\
\hline 1 & $\begin{array}{l}0 . \\
\quad 83\end{array}$ & $\begin{array}{l}1 . \\
38\end{array}$ & 0. & $\begin{array}{l}0 . \\
75\end{array}$ & $\begin{array}{l}0 . \\
\quad 39\end{array}$ & $\begin{array}{l}0 . \\
6\end{array}$ & 6 & 3 \\
\hline 2 & $\begin{array}{l}0 . \\
98\end{array}$ & $\begin{array}{l}1 . \\
\quad 11\end{array}$ & 0. & 0. & $\begin{array}{l}0 . \\
\quad 42\end{array}$ & $\begin{array}{l}0 . \\
\quad 45\end{array}$ & 6 & 6 \\
\hline
\end{tabular}

It is seen that for the first scenario, NSGA-II performs better and for the second scenario, it performs almost equal to NRGA. Therefore, it can be said that overall, the ability of the NSGA-II algorithm to solve the research problem is evaluated higher.

\section{Conclusion}

The model developed in the present study considers two contradictory objectives for SC optimization. As the cost of building and maintaining warehouses increases, the rate of product failure and the likelihood of warehouse failure will decrease.But the costs of the chain also increase.Therefore, it is not possible to provide an optimal response in which both targets are at the same time as their optimal value.In this study, the concept of Pareto boundary and a set of optimal responses have been used.Also, demand is defined as uncertain and dependent on two factors, the demand for the prior period and the remaining time until the expiration of the products. The research problem is solved with both NSGA-II and NRGA algorithms whose parameters of these two algorithms are optimized by the Taguchi method.Each algorithm presents an efficient boundary for each of the two research problems. The two efficient boundaries created by the four criteria 
MID, DM, SM, and NOS were compared and finally concluded that the efficiency of the NSGA-II method in solving the research problem and forming the effective boundary is higher than the NRGA method.

\section{References}

[1]. S. Chopra and P. Meindl, Supply Chain Management: STRATEGY, PLANNING, AND OPERATION, Fifth Edition ed., Pearson, 2013.

[2]. M. Safaei, A. Mehrsai and K. Thoben, "A computational method in analyzing of delivery time uncertainty for highly complex supply networks," Measurement, vol. 55, pp. 549-563, 2014.

[3]. S. Validi, A. Bhattacharya and P. Byrne, "A solution method for a two-layer sustainable supply chain distribution model," Computers \& Operations Research, vol. 54, pp. 204-217, 2015.

[4]. M. Tavana , A. Abtahi , D. Di Caprio, R. Hashemi and Z. Yousefi, "An integrated location-inventory-routing humanitarian supply chain network with pre-and post-disaster management considerations," Socio-Economic Planning Sciences, vol. 64, pp. 21-37, 2018.

[5]. M. Musavi and A. Bozorgi-Amiri, "A multiobjective sustainable hub location-scheduling problem for perishable food supply chain," Computers \& Industrial Engineering, vol. 113, pp. 766-778, 2017.

[6]. B. S. Onggo, J. Panadero, C. G. Corlu and A. A. Juan, "Agri-food supply chains with stochastic demands: A multi-period inventory routing problem with perishable products," Simulation Modelling Practice and Theory, vol. 97, no. 1, p. 101970, 2019.

[7]. M. Shin, H. Lee, K. Ryu, Y. Cho and Y. Son, "A two-phased perishable inventory model for production planning in a food industry," Computers \& Industrial Engineering, vol. 133, no. 1, pp. 175-185, 2019.

[8]. Y. H. Hsiao, M. C. Chen and C. L. Chin, "Distribution planning for perishable foods in cold chains with quality concerns: Formulation and solution procedure," Trends in Food Science \& Technology, vol. 61, no. 1, pp. 80-93, 2017.

[9]. R. Broekmeulen, "Operations management of distribution centers for vegetables and fruits,"
International Transactions in Operational Research, vol. 5, no. 6, pp. 501-508, 1998.

[10]. G. Zhang , W. Habenicht and . W. E. L. Spieß, " Improving the structure of deep frozen and chilled food chain with tabu search procedure," Journal of Food Engineering, vol. 60, no. 1, pp. 67-79, 2003.

[11]. M. Lucas and D. Chhajed, "Applications of location analysis in agriculture: a survey," Journal of the Operational Research Society, vol. 55, no. 6, pp. 561-578, 2004 .

[12]. R. Ahuja , W. Huang, H. Romeijn and D. Morales , "A heuristic approach to the multiperiod single-sourcing problem with production and inventory capacities and perishability constraints," INFORMS Journal on Computing, vol. 19, no. 1, pp. 14-26, 2007.

[13]. O. Ahumada and J. Villalobos, "Application of planning models in the agri-food supply chain: A review," European Journal of Operational Research, vol. 196, no. 1, pp. 1-20, 2009.

[14]. A. Rong , R. Akkerman and M. Grunow, "An optimization approach for managing fresh food quality throughout the supply chain," International Journal of Production Economics, vol. 131, no. 1, pp. 421-429, 2011.

[15]. S. Zanoni and L. Zavanella, "Chilled or frozen? Decision strategies for sustainable food supply chains," International Journal of Production Economics, vol. 140, no. 2, pp. 731736, 2012.

[16]. A. Nagurney and A. Masoumi, "Supply chain network design of a sustainable blood banking system Sustainable Supply Chains," Sustainable Supply Chains: Models, Methods and Public Policy Implications, pp. 49-72, 2012

[17]. D. Agustina, C. Lee and R. Piplani, "Vehicle scheduling and routing at a cross docking center for food supply chains," International Journal of Production Economics, vol. 152, pp. 29-41, 2014.

[18]. M. Lanfranchi, G. Calabrò, A. Pascale, A. Fazio and C. Giannetto, "Household food waste and eating behavior: empirical survey," British Food Journal, vol. 118, no. 12, pp. 3059-3072, 2016.

[19]. M. Musavi and A. Bozorgi-Amiri, " A multi-objective sustainable hub location- 
scheduling problem for perishable food supply chain," Computers \& Industrial Engineering, vol. 113, pp. 766-778, 2017.

[20]. Z. Rafie-Majd, S. Pasandideh and B. Naderi, "Modelling and solving the integrated inventorylocation-routing problem in a multi-period and multi-perishable product supply chain with uncertainty: Lagrangian relaxation algorithm," Computers \& Chemical Engineering, vol. 109, no. 4, pp. 9-22, 2018.

[21]. M. Tavana , A. Abtahi , D. Di Caprio, R. Hashemi and R. Yousefi-Zenouz, "An integrated location-inventory-routing humanitarian supply chain network with pre-and post-disaster management considerations," Socio-Economic Planning Sciences, vol. 64, no. 2, pp. 21-37, 2018.
[22]. H. Hsu, "A Compromise Programming Model for Perishable Food Logistics under Environmental Sustainability and Customer Satisfaction," in In 2019 IEEE 6th International Conference on Industrial Engineering and Applications (ICIEA), Tokyo, Japan, 2019.

[23]. L. Li, Y. Yang and G. Qin, "Optimization of Integrated Inventory Routing Problem for Cold Chain Logistics Considering Carbon Footprint and Carbon Regulations," Sustainability, vol. 11, no. 17, pp. 1-22, 2019.

[24]. H. Guo, C. Li, Y. Zhang, C. Zhang and Y. Wang, "A nonlinear integer programming model for integrated location, inventory, and routing decisions in a closed-loop supply chain," Complexity, vol. 2018, pp. 1-17, 2018.

[25]. M. Safaei, Delivery time uncertainty in dynamic supply networks, Aachen: Shaker, 2014. 